\title{
Thermal Mismatch Effect and High-Temperature Tensile Performance Simulation of Hybrid CMC and Superalloy Bolted Joint by Progressive Damage Analysis
}

\author{
Shuyuan Zhao $\mathbb{D}^{1},{ }^{1}$ Jianglong Dong, ${ }^{1}$ Chao Lv, ${ }^{2}$ Zhengyu Li, ${ }^{1}$ Xinyang Sun, ${ }^{3}$ \\ and Wenjiao Zhang $\mathbb{D}^{4}$ \\ ${ }^{1}$ National Key Laboratory of Science and Technology on Advanced Composites in Special Environments, Harbin Institute \\ of Technology, Harbin 150080, China \\ ${ }^{2}$ China Academy of Aerospace Aerodynamics, Beijing 100074, China \\ ${ }^{3}$ School of Aeronautics and Astronautics, Harbin Institute of Technology, Harbin 150001, China \\ ${ }^{4}$ Engineering College, Northeast Agricultural University, Harbin 150030, China
}

Correspondence should be addressed to Shuyuan Zhao; angel.zsy@126.com and Wenjiao Zhang; zhangwenjiao@neau.edu.cn

Received 1 October 2019; Accepted 28 January 2020; Published 11 March 2020

Academic Editor: Nicolas Avdelidis

Copyright (C) 2020 Shuyuan Zhao et al. This is an open access article distributed under the Creative Commons Attribution License, which permits unrestricted use, distribution, and reproduction in any medium, provided the original work is properly cited.

The hybrid CMC and superalloy bolted joints have exhibited great potential to be used as thermostructural components of reusable space transportation systems, given the respective strengths of these two materials. In the high temperature excursion of the hybrid joints with the aircrafts and space vehicles, the substantial difference in thermal expansion coefficients of CMC and superalloy materials will induce complex superposition of initial assembly stress, thermal stress, and tensile stress around fastening area, which might lead to unknown failure behavior of joint structure. To address this concern, a finite element model embedded with progressive damage analysis was established to simulate the thermostructural behavior and high-temperature tensile performance of single-lap, single-bolt $\mathrm{C} / \mathrm{SiC}$ composite and superalloy joint, by using the ABAQUS software. It was found that the initial stiffness of the $\mathrm{CMC} /$ superalloy hybrid bolted joints decreases with the rise of applied temperature under all bolt-hole clearance levels. However, the load-bearing capacity varies significantly with the initial clearance level and exposed temperature for the studied joint. The thermal expansion mismatch generated between the CMC and superalloy materials led to significant changes in the assembly preload and bolt-hole clearance as the high-temperature load is applied to the joint. The evolution in the thermostructural behavior upon temperature was then correlated with the variations in stiffness and failure load of the joints. The provided new findings are valuable for structural design and practical application of the hybrid CMC/superalloy bolted joints at high temperatures in next-generation aircrafts.

\section{Introduction}

Continuous fiber-reinforced ceramic matrix composites (CMC) are one of the most important key technologies in the development of reusable space transportation systems, e.g., FOTON 9 and FOTON-M2 [1, 2], EXPRESS [2], and SHEFEX [3] missions, due to their high specific stiffness and strength, low thermal expansion coefficient, nonbrittle failure nature, and excellent environmental stability at elevated temperatures [4-7]. To realize their successful applications in vehicles, the CMC are often connected with super- alloy primary and secondary structures by mechanical joints. Among the existing joint forms, bolted joint has drawn much attention because of its high load-carrying capability, easy assembly and disassembly, and excellent damages tolerance. As most of the failures take place in the mechanical fastening area of joint structures, the design of bolted joint is of critical importance in improving load-bearing efficiency and maintaining structural integrity of the overall structure. However, the mechanical strength and failure behavior of bolted joint are generally influenced by numerous factors, such as fastener types, joint geometry, and assembly 
conditions, posing a major technical challenge to aircraft engineers. Special concern arises for the CMC and superalloy hybrid bolted joints when they are in high temperature excursions with the aircraft and space vehicles. The thermal expansion coefficients of CMC and superalloy materials usually differ 2-3 times, causing significant thermal mismatch effect. This effect will induce complex thermal stress and strain distributions at a hole-edge area and change assembly parameters of the joint [7], which might lead to unknown failure behavior of joint structure. Therefore, it is essential to evaluate the thermostructural effect and resulted in influence on failure behaviors of the CMC and superalloy bolted joint structure at high applied temperatures.

In previous research on strength and failure behaviors of CMC joint structures, Mei et al. [8] experimentally investigated the tensile properties and oxidation behavior of $2 \mathrm{D}$ $\mathrm{C} / \mathrm{SiC}$ bolts prepared by chemical vapor infiltration in a simulated reentry environment. The results showed that all the tensile strengths of $2 \mathrm{D} \mathrm{C} / \mathrm{SiC}$ bolts at test temperatures of $1300^{\circ} \mathrm{C}, 1600^{\circ} \mathrm{C}$, and $1800^{\circ} \mathrm{C}$ decreased, respectively, retaining $85 \%, 92 \%$, and $94 \%$ of the virgin properties at room temperature. The tensile strengths and times to failure of $2 \mathrm{D}$ $\mathrm{C} / \mathrm{SiC}$ bolts slightly increased with increase of test temperature. $\mathrm{Li}$ et al. [9] studied the damage mode and fracture load of $\mathrm{C} / \mathrm{SiC}$ joints via a comparison between the results of simulations and experiments. The maximum stress failure criterion was used to determine the damage of $\mathrm{C} / \mathrm{SiC}$ composites in simulations. The influences of hole parameters including ratios of edge distance to diameter, width to diameter, and hole distance to diameter, on the mechanical properties of $\mathrm{C} / \mathrm{SiC}$ joints with pins or bolts were studied. Zhao et al. [10] performed failure analyses of open-hole $\mathrm{C} / \mathrm{SiC}$ composite laminates with different failure criteria and material degradation models, among which the most suitable combination was filtered by comparing the numerical results with existing experimental data. Furthermore, the failure process of a three-bolt $\mathrm{C} / \mathrm{SiC}$ composite joint was predicted using the proposed progressive failure model. Among the limited research on CMC joints, little attention was paid on the studies of thermal mismatch effect and hightemperature tensile behavior of $\mathrm{CMC}$ /superalloy bolted joints. To address the above deficiencies in open literatures, a 3D finite element model coupled with progressive damage analysis is firstly carried out to predict tensile performance and failure behavior of single-lap, single-bolt hybrid CMC/superalloy joint. A macroscopic phenomenological constitutive model is employed to describe the nonlinear stress-strain behavior of $2 \mathrm{D}$ woven $\mathrm{C} / \mathrm{SiC}$ composite. The preload loosening and variation of bolt-hole clearance caused by thermal expansion mismatch of the CMC and superalloy materials at high-temperature loading were evaluated, and their resultant influence on high-temperature tensile behavior and damage mechanisms will be discussed for the studied hybrid bolted joint.

\section{Constituent Model and Damage Mechanism of 2D C/SiC Composites}

When the damage occurs in the $2 \mathrm{D}$ plain-woven $\mathrm{C} / \mathrm{SiC}$ composite, the stress and strain relationship for transversal isotropic material can be written as [11]

$$
\left\{\begin{array}{l}
d \varepsilon_{1} \\
d \varepsilon_{2} \\
d \varepsilon_{3} \\
d \varepsilon_{4} \\
d \varepsilon_{5} \\
d \varepsilon_{6}
\end{array}\right\}=\left[\begin{array}{cccccc}
1 / E_{1} & -v_{21}^{0} / E_{2}^{0} & -v_{31}^{0} / E_{3}^{0} & 0 & 0 & 0 \\
-v_{12}^{0} / E_{1}^{0} & 1 / E_{2} & -v_{32}^{0} / E_{3}^{0} & 0 & 0 & 0 \\
-v_{13}^{0} / E_{1}^{0} & -v_{23}^{0} / E_{2}^{0} & 1 / E_{3}^{0} & 0 & 0 & 0 \\
0 & 0 & 0 & 1 / G_{12} & 0 & 0 \\
0 & 0 & 0 & 0 & 1 / G_{13}^{0} & 0 \\
0 & 0 & 0 & 0 & 0 & 1 / G_{23}^{0}
\end{array}\right]\left\{\begin{array}{c}
d \sigma_{1} \\
d \sigma_{2} \\
d \sigma_{3} \\
d \sigma_{4} \\
d \sigma_{5} \\
d \sigma_{6}
\end{array}\right\}=\mathbf{S d \sigma}
$$

where $E_{i}^{0}(i=1,2,3)$ is the initial elastic modulus of the composite in principle direction 1,2 , and 3, respectively. $G_{13}^{0}$ and $G_{23}^{0}$ are the initial shear modulus of the composite at 1-3 and 2-3 shear plane, respectively. $v_{\mathrm{ij}}^{0}(i, j=1,2,3)$ is the initial Poisson ratio. $E_{i}(i=1,2), G_{12}$, and $S$ are, respectively, the elastic modulus, shear modulus, and flexibility matrix when damage occurs inside the composite.

Extensive experimental observations by researchers demonstrated that $\mathrm{C} / \mathrm{SiC}$ composites exhibit nonlinearity and pseudoplasticity under uniaxial tensile and shear loading [12]. When the external load is smaller than a proportional limit, the material performs as linear elastic behavior. When external load increases beyond this proportional limit, nucleation and propagation of microcracks initiates until the material fails. And the stress-strain behavior of CMCs presents a nonlinear form due to the progressive damage of matrix cracks, interface slipping and debonding, fiber failure, and fiber pull-out during tensile loading. The damage progression will dissipate the energy of external load and reduce the stiffness of material. To address the nonlinear stressstrain behavior of CMC materials, various approaches have been proposed in literatures and can be essentially grouped 


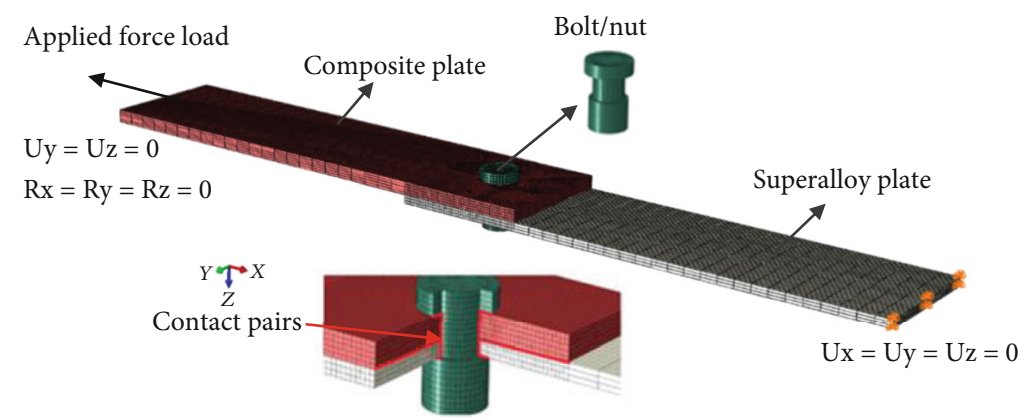

Figure 1: Finite element model and set contact pairs of a 2D C/SiC composite superalloy bolted joint structure.

into three categories: (1) phenomenological damage mechanics-based approaches [13-16], (2) micromechanicsbased approaches [17-21], and (3) multiscale modeling approaches [22-24]. To achieve a good balance between computational efficiency and accuracy, for the current analysis, a macroscopic constituent model proposed by $\mathrm{Li}$ [13] is adopted here to characterize the mechanical behavior of $2 \mathrm{D}$ plain-woven $\mathrm{C} / \mathrm{SiC}$ composite materials. Their model will be described here briefly. The experimental stress-strain relationships under uniaxial tensile and shear loading for the material are fitted with five-order polynominal function. And then, the tangent modulus at various strain levels used for damage analysis is obtained through derivation to the detectable strain according to the fitted stress-strain relationship.

$$
\begin{aligned}
\mathrm{E}_{i}^{\mathrm{tan}}= & \frac{d \sigma_{i}}{d \varepsilon_{i}}=A_{1}+2 A_{2} \varepsilon_{i}+3 A_{3} \varepsilon_{i}^{2}+4 A_{4} \varepsilon_{i}^{3} \\
& +5 A_{5} \varepsilon_{i}^{4}\left(0 \leq \varepsilon_{i} \leq \varepsilon_{i}^{f}, i=1,2\right) \\
G_{12}^{\mathrm{tan}}= & \frac{d \tau_{12}}{d \gamma_{12}}=B_{1}+2 B_{2} \gamma_{12}+3 B_{3} \gamma_{12}^{2}+4 B_{4} \gamma_{12}^{3}+5 B_{5} \gamma_{12}^{4}
\end{aligned}
$$

where $\varepsilon_{i}^{f}$ is the tensile fracture strain. $\gamma_{12}^{f}$ is the shear fracture strain in the 1-2 plane. $A_{j}$ and $B_{j}(j=1,2, \cdots 5)$ are the fitted coefficients. When the tensile strain $\varepsilon_{i}$ and shear strain $\gamma_{12}$ are equal to zero, the $\mathrm{E}_{i}^{\mathrm{tan}}$ and $G_{12}^{\mathrm{tan}}$ are the initial elastic modulus $E_{1}^{0}$ and shear modulus $G_{12}^{0}$ of the $\mathrm{C} / \mathrm{SiC}$ composite.

Under tensile and shear unloading or reloading processes, the elastic modulus $E_{1}^{u}$ and shear modulus $G_{12}^{u}$ can be fitted by using a logical function with the associated strain as given:

$$
\begin{gathered}
\mathrm{E}_{i}^{u}=A_{6}+\frac{A_{7}-A_{6}}{1+\left(\varepsilon_{i}^{m} / x_{0}\right)^{p_{0}}} \quad\left(\varepsilon_{i} \leq \varepsilon_{i}^{m}, i=1,2\right) \\
\mathrm{G}_{12}^{u}=B_{6}+\frac{B_{7}-B_{6}}{1+\left(\left|\gamma_{12}^{m}\right| / x_{1}\right)^{p_{1}}} \quad\left(\left|\gamma_{12}\right| \leq\left|\gamma_{12}^{m}\right|\right)
\end{gathered}
$$

where $A_{6}, A_{7}, p_{0}, x_{0}$, and $B_{6}, B_{7}, p_{1}$, and $x_{1}$ are the shape parameters of each logical function.
The stress and strain response of composites under compressive loading is approximate to linear elastic relation, and the selection of compressive modulus is divided into two circumstances. When the stress level of the material exceeds a microcrack closure point $\mathrm{C}\left(\varepsilon^{r}, \sigma^{r}\right)$, closure of the microcracks leads partially to recovery of initial elastic property $\mathrm{E}_{i}^{0}$. Otherwise, the compressive modulus is the same as the unloading modulus in tensile loading and unloading curve.

$$
\begin{aligned}
& \sigma_{i}=\mathrm{E}_{i}^{0} \varepsilon_{i} \quad\left(\varepsilon_{i} \geq \varepsilon_{i}^{b}, \sigma_{i} \leq \sigma_{i}^{r}, i=1,2\right) \\
& \sigma_{i}=\mathrm{E}_{i}^{u} \varepsilon_{i} \quad\left(\sigma_{i}^{r} \leq \sigma_{i} \leq 0, i=1,2\right)
\end{aligned}
$$

where $\varepsilon_{i}^{c}$ is the compressive fracture strain and $\sigma^{r}$ is the stress at the microcrack closure point $\mathrm{C}$.

\section{Finite Element Modeling}

A 2D plain-woven $\mathrm{C} / \mathrm{SiC}$ composite to $\mathrm{GH} 4169$ superalloy, single-bolt, single-lap joint structure will be studied here. The finite element model was established to simulate quasistatically tensile loading of the hybrid $\mathrm{C} / \mathrm{SiC}$ compositesuperalloy bolted joint via Abaqus/standard software, as illustrated in Figure 1. Both the CMC plate and superalloy plate are $120 \mathrm{~mm}$ long, with $50 \mathrm{~mm}$ griping length. The thickness of the CMC plate and GH4169 alloy plate is $3.0 \mathrm{~mm}$ and $1.5 \mathrm{~mm}$, respectively. The two plates are assembled together using a $5.0 \mathrm{~mm}$ diameter bolt made of GH4141 alloy. The $2 \mathrm{D}$ woven $\mathrm{C} / \mathrm{SiC}$ composite is assumed as transversal isotropic material, and the constituent model exhibits nonlinear behavior. The measured stress-strain curves under uniaxial tension and shear loading for a $2 \mathrm{D}$ plain-woven $\mathrm{C} / \mathrm{SiC}$ composite material provided by material suppliers and the fitted results are shown in Figure 2. The rest of mechanical and thermal properties of the composite material used for analysis are summarized in Table 1, respectively. Due to a higher yield strength of superalloy than that of CMC, the failure process of the bolted joint is dominated by the composite plate. Therefore, only elastic behavior of the superalloy plate and bolt was considered in this analysis. The assigned mechanical and thermal properties of GH4169 and GH4141 alloys as a function of temperature are obtained from China Aviation Materials Handbook $[25,26]$, as shown in Table 2. Three-dimensional eight-node reduced- 


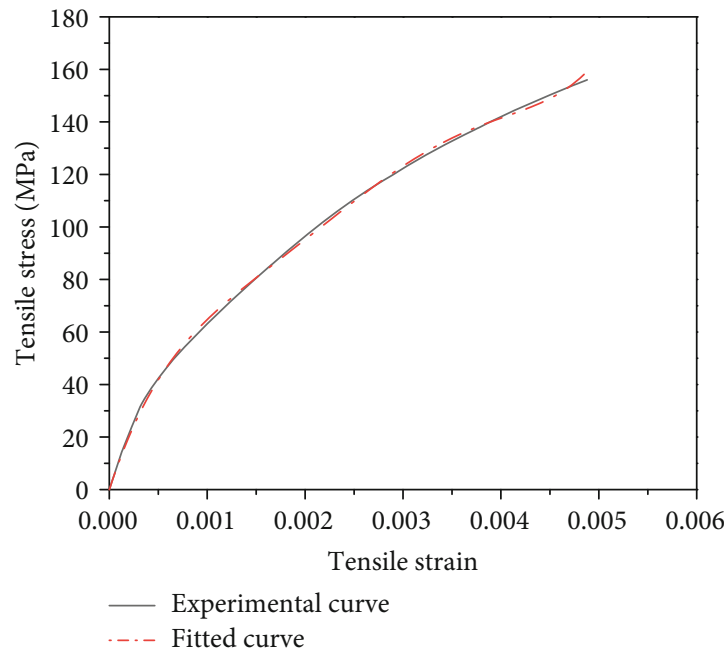

(a)

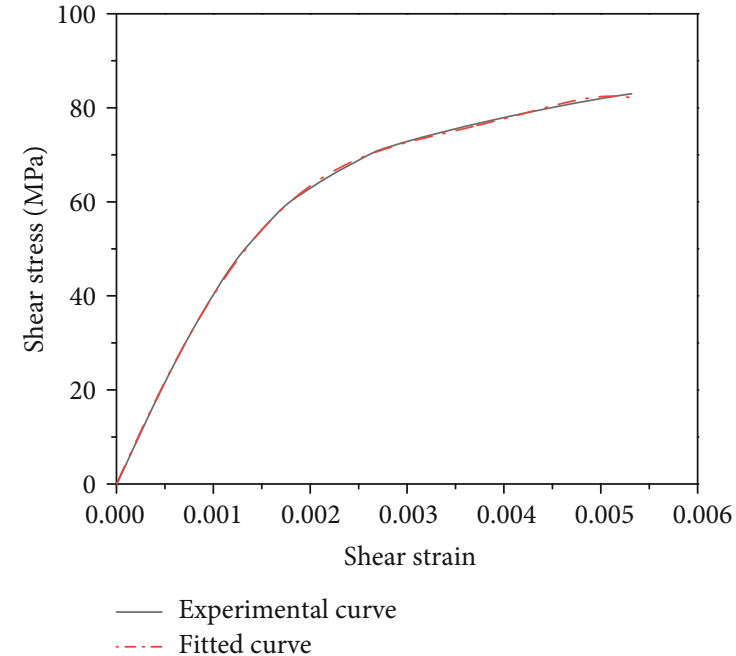

(b)

Figure 2: The measured stress-stain curves provided by material suppliers and the fitted results for a 2D plain-woven C/SiC composite plate under uniaxial tension (a) and shear (b) loading.

TABLE 1: Mechanical and thermal properties of 2D plain-woven $\mathrm{C} / \mathrm{SiC}$ composite material.

\begin{tabular}{lcc}
\hline Property & Symbol & Value \\
\hline Initial elastic modulus (GPa) & $E_{11}=E_{22}$ & 114.13 \\
& $E_{33}$ & 88.90 \\
Initial shear modulus (GPa) & $G_{12}$ & 45.12 \\
& $G_{13}=G_{23}$ & 25.63 \\
Poisson's ratio & $v_{12}$ & 0.13 \\
& $v_{13}=v_{23}$ & 0.26 \\
Tensile strength (MPa) & $X_{\mathrm{t}}=Y_{\mathrm{t}}$ & 156 \\
& $Z_{\mathrm{t}}$ & 350 \\
Compressive strength $(\mathrm{MPa})$ & $X_{\mathrm{c}}=Y_{\mathrm{c}}$ & 350 \\
& $Z_{\mathrm{c}}$ & 420 \\
In-plane shear strength $(\mathrm{MPa})$ & $S_{12}=S_{13}=S_{23}$ & 83 \\
Thermal expansion coefficient $\left(10^{-6} /{ }^{\circ} \mathrm{C}\right)$ & $\mathrm{CTE}$ & 5.12 \\
\hline
\end{tabular}

integration C3D8R elements with hourglass control were used to discretize the composite laminates, superalloy plate, and mechanical fastener. To improve computational efficiency, hexagonal heads for bolt and nut were simplified as round heads, and the bolt and nut were modeled as entirety to decrease contact surfaces. Five contact pairs for the joint structure were defined between fastener shank and holes of plates, fastener head or nut and the outer surfaces of the two plates, and the faying surface of two plates. A finite sliding contact and surface to surface contact formulations were adopted between all contact interfaces in the model. A classic Coulomb friction was assigned to all contacted surfaces with a friction coefficient of 0.3 . Bolt-hole clearance values varying from 0 to $1.2 \%$ were, respectively, set to the joint through setting interference fit values of the contact pairs between fastener shank and holes in two plates. A $6 \mathrm{kN}$ preload was applied for all the considered joints through Bolt load func- tion in ABAQUS. The right end of the superalloy plate was held fixed in all three translational directions (Ux, Uy, and $\mathrm{Uz}$ ). The left end of the composite plate was held fixed in two translational directions ( $\mathrm{Uy}$ and $\mathrm{Uz}$ ) and three rotational directions ( $\mathrm{Rx}, \mathrm{Ry}$, and $\mathrm{Rz}$ ), while a uniform force load was applied along $\mathrm{Ux}$ direction to mimic a quasistatic tensile loading. To examine the temperature-dependent behavior of tensile performance, uniform temperature loads of $25^{\circ} \mathrm{C}$, $150^{\circ} \mathrm{C}, 300^{\circ} \mathrm{C}, 450^{\circ} \mathrm{C}, 600^{\circ} \mathrm{C}$, and $750^{\circ} \mathrm{C}$ were, respectively, imposed to the entire joint structures.

\section{Progressive Damage Analysis Method and Its Validation}

To implement a progressive failure analysis of hybrid $\mathrm{C} / \mathrm{SiC}$ composite and superalloy bolted joint structure, a userdefined subroutine UMAT including the nonlinear constitutive model, failure criterion, and material degradation rule was embedded into the general package ABAQUS ${ }^{\circledR}$. In this subroutine, the predefined field variables were described as functions of material properties, which was then used for mechanical behavior expression of any material point. Figure 3 shows the flowchart for progressive damage analysis of the hybrid joint. The proposed analysis method starts with the generation of a finite element model for the studied bolted joint by using the material properties, geometrical parameters, boundary conditions, initial load, and load step as inputs. Then, a nonlinear stress analysis is carried out to calculate stress at each element on the bolted joint using the above-described constituent models. For the current analysis, Tsai-Wu strength criterion [27] is adopted for evaluation of failure occurrence on basis of the calculated structural stresses. If the failure criterion is violated, the applied load is increased by a load increment and the stiffness parameters for CMC are updated in accordance with the obtained stress levels. Otherwise, if the final structure failure is not satisfied, the material stiffness parameters are reduced to $1 \%$ of its 
TABLE 2: Mechanical and thermal properties of superalloy plate and bolt/nut.

\begin{tabular}{|c|c|c|c|}
\hline Property & Temperature $\left({ }^{\circ} \mathrm{C}\right)$ & GH4169 & GH4141 \\
\hline \multirow{8}{*}{ Young's moduli (GPa) } & 20 & 204 & 221 \\
\hline & 300 & 181 & 216 \\
\hline & 400 & 176 & 210 \\
\hline & 500 & 160 & 205 \\
\hline & 550 & 160 & 200 \\
\hline & 600 & 150 & 195 \\
\hline & 650 & 146 & 188 \\
\hline & 700 & 141 & 182 \\
\hline \multirow{8}{*}{ Poisson's ratio } & 20 & 0.3 & 0.3 \\
\hline & 100 & 0.3 & 0.3 \\
\hline & 200 & 0.3 & 0.3 \\
\hline & 300 & 0.3 & 0.3 \\
\hline & 400 & 0.31 & 0.3 \\
\hline & 500 & 0.32 & 0.3 \\
\hline & 600 & 0.32 & 0.3 \\
\hline & 700 & 0.33 & 0.3 \\
\hline \multirow{8}{*}{ Coefficient of thermal expansion $\left(10^{-6} \cdot{ }^{\circ} \mathrm{C}^{-1}\right)$} & $20-100$ & 11.8 & 10.5 \\
\hline & $20-200$ & 13 & 11.7 \\
\hline & $20-300$ & 13.5 & 12.2 \\
\hline & $20-400$ & 14.1 & 12.8 \\
\hline & $20-500$ & 14.4 & 13.1 \\
\hline & $20-600$ & 14.8 & 13.5 \\
\hline & $20-700$ & 15.4 & 14.2 \\
\hline & $20-800$ & 17 & 15.0 \\
\hline
\end{tabular}

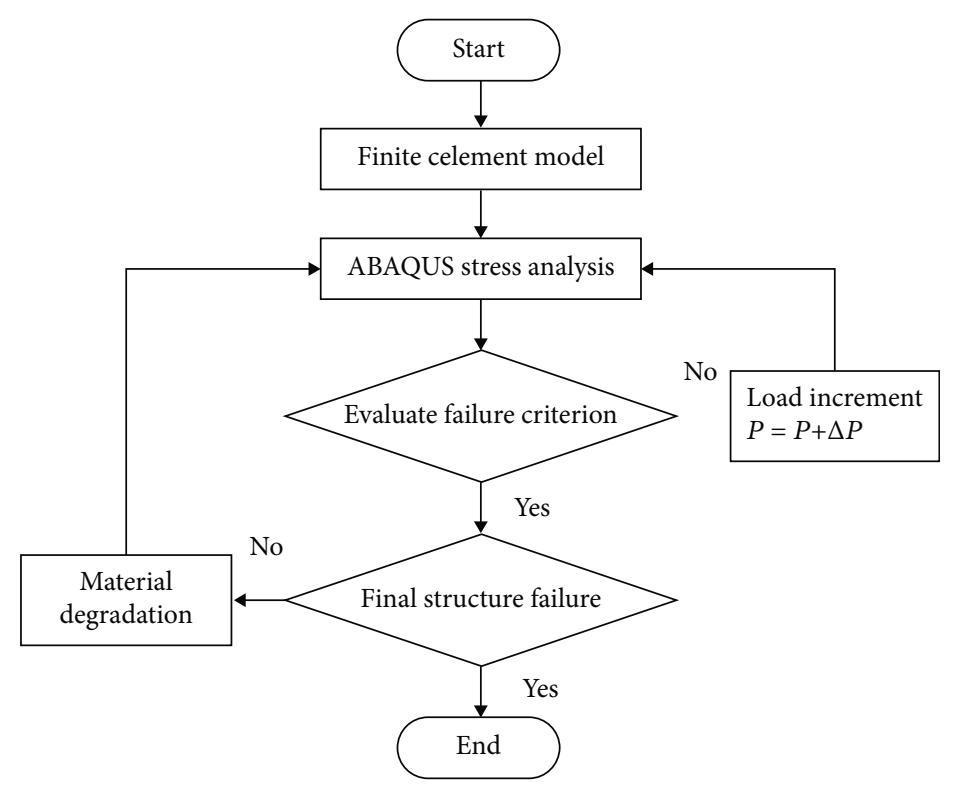

FIGURE 3: Flowchart for progressive damage analysis of the hybrid joint.

undamaged value for the $\mathrm{C} / \mathrm{SiC}$ composite. The simulation is terminated until encountering final failure of the composite structure or severe convergence difficulties.
To validate the proposed damage analysis method for the $2 \mathrm{D}$ woven $\mathrm{C} / \mathrm{SiC}$ composite materials, cyclic loading and unloading tensile and shear loading as well as uniaxial 


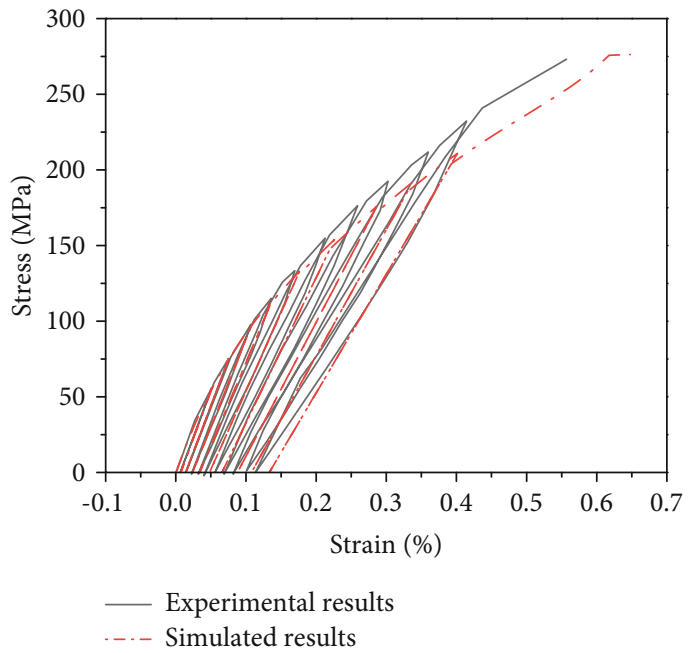

(a)

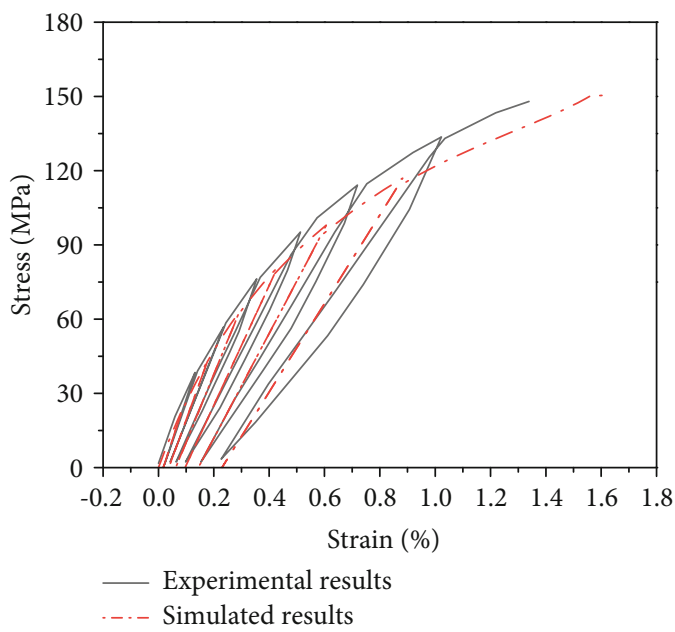

(b)

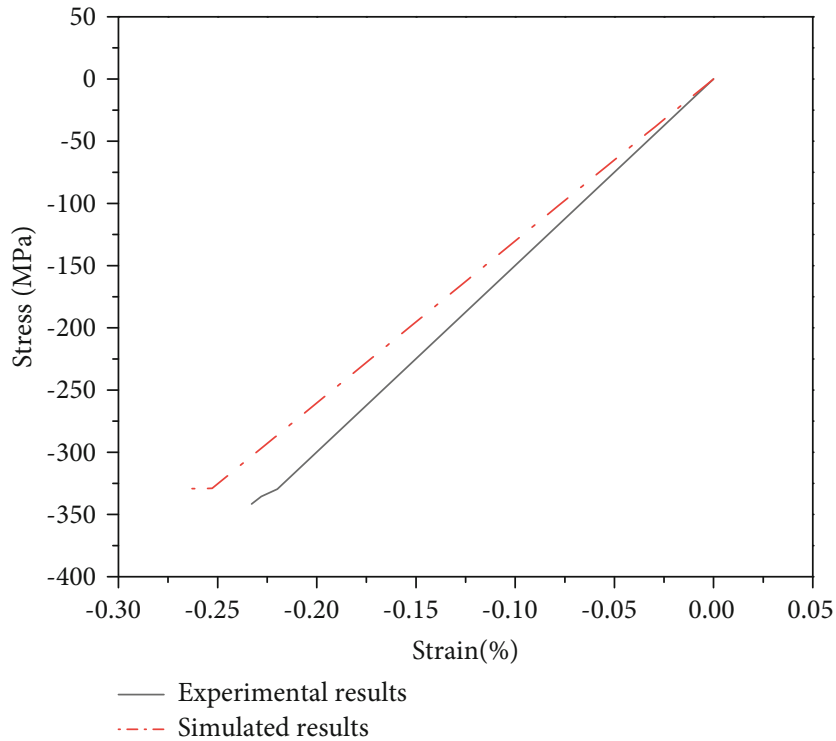

(c)

FIGURE 4: Comparison of simulated stress and strain relations with experimental results under tensile (a) and shear (b) loading/unloading and uniaxial compressive loading (c) processes of the $2 \mathrm{D} \mathrm{C/SiC}$ composite samples in $\mathrm{Li}$ [13].

compression loading conditions of the composite samples were simulated according to the provided experimental conditions in Ref. [13]. A uniaxial tensile loading of an open-hole laminate was also simulated for lack of data on hybrid $\mathrm{C} / \mathrm{SiC}$ composite and superalloy bolted joint in open publications. The geometric configuration, test conditions, and measured stress-strain curves of $2 \mathrm{D}$ woven $\mathrm{C} / \mathrm{SiC}$ composite samples for this validation were given in the Ref. [13]. The predicted stress-strain curves as well as experimental results under tensile and shear loading/unloading and uniaxial compressive loading processes of the $2 \mathrm{D} \mathrm{C/SiC}$ composite samples were shown in Figures 4 and 5. As can be seen from Figure 4, the simulated stress and strain relations are in good correspondence with the experimental results under each loading circumstance. The comparison of the simulated and experimental results [13] for the open-hole CMC laminate are as shown in Figure 5 which demonstrated that the predicted strength of $135.5 \mathrm{MPa}$ agrees with the experimental value of $150 \mathrm{MPa}$, with a relative error of $9.6 \%$. Considering that various factors might introduce errors between the measured and predicted results, such as the $\mathrm{SiC}$ antioxidant coating deposited on the experimental specimen surface, scattering of experimental data caused by intrinsic defects, simplifications in finite element modeling, and the selected failure criterion and degradation rule in the progressive damage simulation. This error level is acceptable in engineering applications, which validates the effectiveness of the proposed progressive failure model in this paper.

\section{Results and Discussions}

5.1. Thermal Mismatch Induced Assembly Parameter Changes of the Joints. In practical engineering, the hybrid $\mathrm{CMC}$ and superalloy joints are often assembled at room 


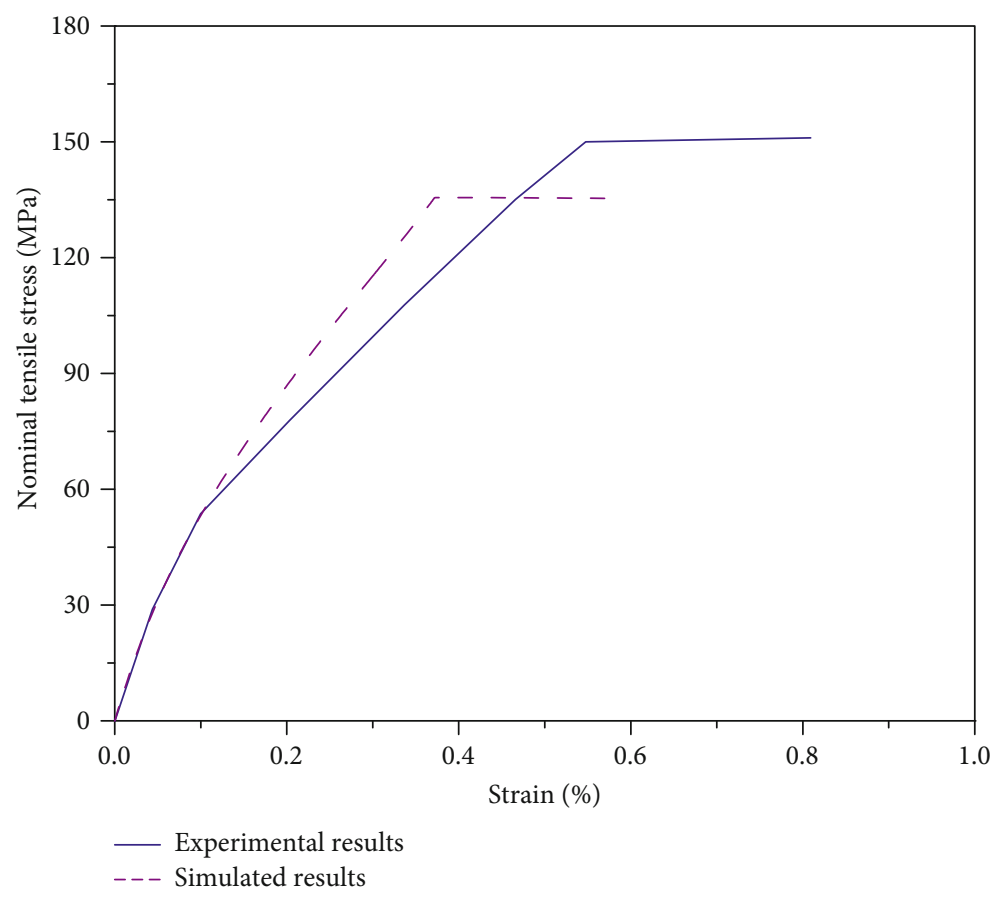

FIGURE 5: Comparison of simulated tensile stress and strain relationship with experimental results in Li [13] for 2D woven C/SiC composite open-hole plate.

temperature, and then used under high-temperature conditions. High-temperature thermal exposure will induce dramatic thermal mismatch due to difference in thermal expansion coefficient of CMC and superalloy materials. However, the assembly parameters of bolted joints can significantly affect damage progression at the hole edges as well as bearing behavior of mechanically fastened composite joints. Therefore, the residual preload and bolt-hole clearance before and after applying temperature loads to the joints are firstly extracted from the finite element models with a fixed $6000 \mathrm{~N}$ initial preload and 0-1.2\% bolt-hole clearances, and the results are depicted in Figures 6 and 7, respectively. For the neat-fit joint, when the imposed temperature loads were higher than $450^{\circ} \mathrm{C}$, damage occurred around hole edges of the CMC plate, which led to premature failure of the joint structure before applying tensile load. Therefore, the joint parameters of these cases are absent in these figures. From Figure 6, A remarkable decline in the assembly preload can be observed for four bolt-hole clearance levels. When the bolt-hole clearances is 0 , the preload dropped from $6000 \mathrm{~N}$ at room temperature to $4022 \mathrm{~N}$ at $450^{\circ} \mathrm{C}$, whereas the curves for the other three clearance cases (0.4\%-1.2\%) are almost the same but with a steeper slope and the corresponding preloads keep to decrease to $3759 \mathrm{~N}$ at $450^{\circ} \mathrm{C}$ and to about $1871 \mathrm{~N}$ at $750^{\circ} \mathrm{C}$. Figure 7 presents the variation of bolt-hole clearance with temperature under $6000 \mathrm{~N}$ preload for both CMC and superalloy bolted joint. After the temperature load imposed to the joint, a slight increase in the bolt-hole clearance for superalloy plate could be detected for all the considered cases. However, an adverse trend is found in the clearance for the $\mathrm{CMC}$ plate. As the higher temperature is applied, there even

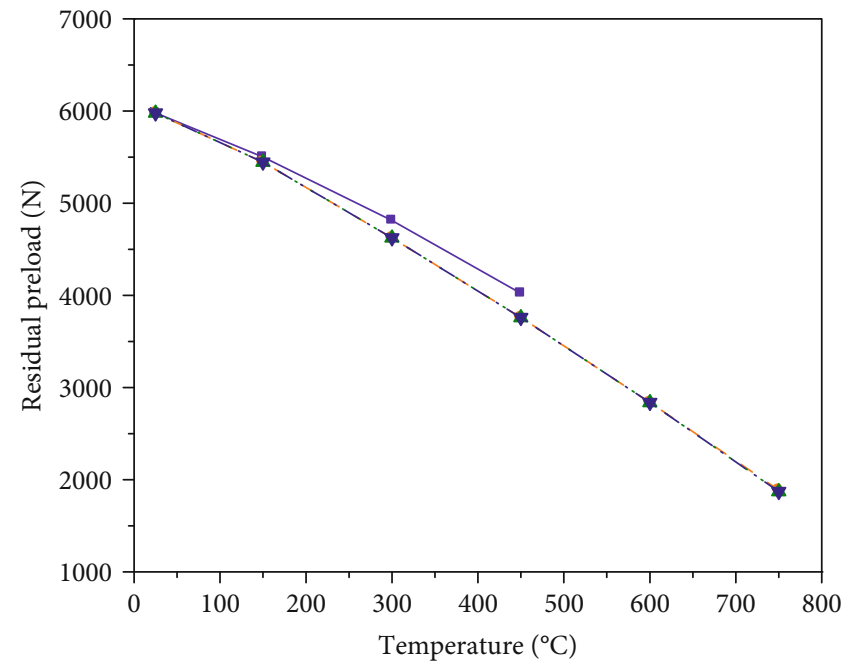

Bolt-hole clearance

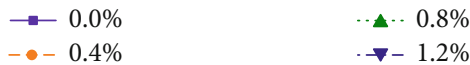

FIGURE 6: Variation of residual preload with temperature for the studied CMC and superalloy bolted joint.

occurs a small interference between the CMC plate and bolt shank for the initial neat-fit case under $450^{\circ} \mathrm{C}$. Similar phenomenon can also be found for the joint with $0.4 \%$ clearance at temperature of $750^{\circ} \mathrm{C}$. The changes in the preload and clearances before and after applying temperature loads could be mainly attributed to thermal expansion mismatch 


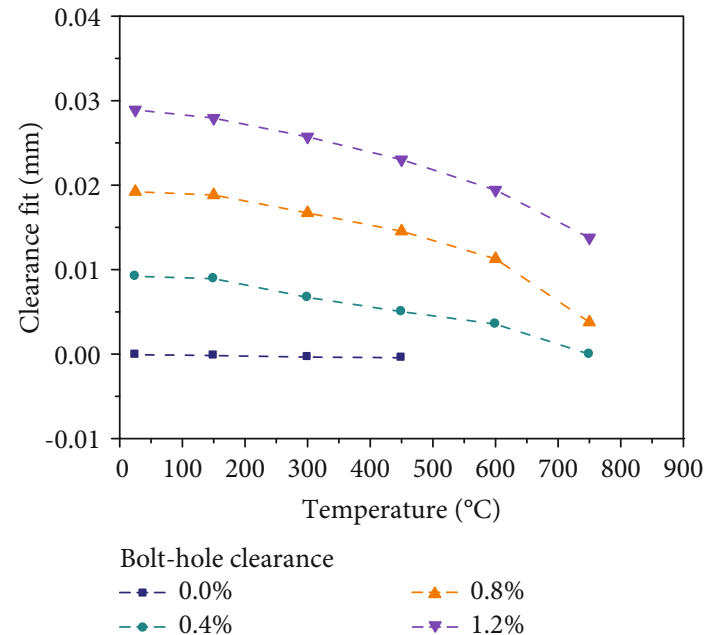

(a)

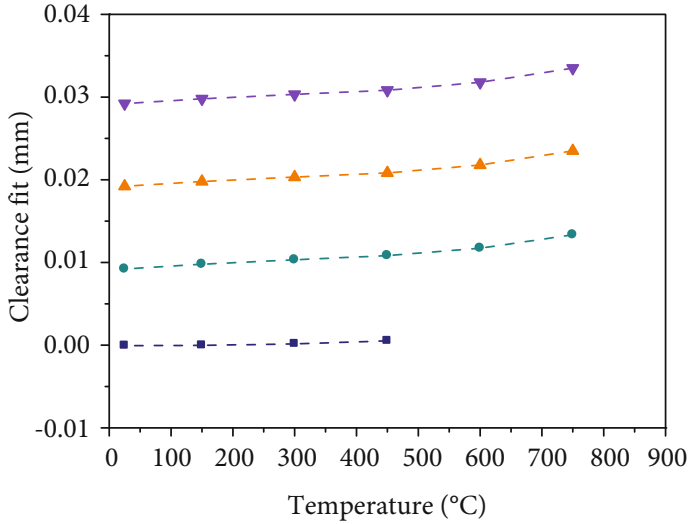

Bolt-hole clearance

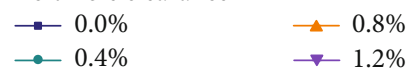

(b)

FiguRE 7: Variation of bolt-hole clearance with temperature for the studied CMC and superalloy bolted joint. (a) CMC plate. (b) Superalloy plate.

between CMC and superalloy materials. Higher thermal expansion coefficient of superalloy plate and bolt resulted in more substantial thermal strain of superalloy bolt along thickness direction than that of CMC, which undoubtedly contributes to stress relaxation, as exampled by the simulated peak Mises stress at $20^{\circ} \mathrm{C}$ and $750^{\circ} \mathrm{C}$ for the joint with $1.2 \%$ clearance after applying preload and temperature but not tensile load in Figure 8. With the same reason, the gap between the bolt and hole became narrower, whereas it grows larger between the metallic plate and bolt-hole part. The comparison of contact compressive stress at temperatures of $25^{\circ} \mathrm{C}$ and $750^{\circ} \mathrm{C}$ for the joint with $0.4 \%$ and $1.2 \%$ clearance after applying preload and temperature but not tensile load to the joint is illustrated in Figure 9. Except the compressive force on the upper and lower contact surfaces of the fastener being produced like the joint with $1.2 \%$ clearance, extra contact compressive stress is generated on the contact surface of the CMC plate and bolt shank for the joint with $0.4 \%$ initial clearance at $750^{\circ} \mathrm{C}$. The compressive stress around hole edge which resulted from the interference improves the fiction force at the contact interface and stiffness in thickness, and thus the preload reduction is inhibited for the neat-fit joint and $0.4 \%$ clearance joint at temperature of $750^{\circ} \mathrm{C}$, in comparison with other clearance cases working at the same temperature.

5.2. High-Temperature Tensile Performance of the Joints. The hig-temperature tensile performances of the hybrid $\mathrm{CMC} / \mathrm{su}$ peralloy bolted joint were simulated under various bolt-hole clearance levels by using the established progressive damage analysis method. The simulated load-displacement curves in tensile loading of the mechanically fastened joints are illustrated in Figure 10. As can be clearly seen from Figure 10, under all bolt-hole clearance levels, the slope of curves shows declining trend, which means that the initial stiffness of the hybrid bolted joints drops with the rise of applied tempera- ture. The stiffness reduction is possibly due to the fact that the continuous preload relaxation upon temperature rising as we discussed above lessens the friction force on the contact surface of two plates, which is used for resisting the external tensile load. Soykok et al. [28] carried out an experimental failure analysis to determine the effects of thermal condition and tightening torque on the failure behavior of single-lap double serial fastener glass fiber/epoxy composite joints. They found that the load carried by joint for the same bolthole displacement rate was reduced as the temperature rises from $40^{\circ} \mathrm{C}$ to $80^{\circ} \mathrm{C}$. This seems to be in accordance with the present findings on variation of initial stiffness of the joint structure with temperature. Their results also demonstrated that the joint performance is highly affected by polymer material degradation, thus failure gradually occurs at lower stress levels by increasing temperature. In comparison with the room temperature results, the load-carrying capacity of the joint dropped to $70 \%$ at $80^{\circ} \mathrm{C}$. In contrast to their results, the influence of temperature on load-bearing capacity is diverse for different clearance levels for the studied hybrid $\mathrm{CMC} /$ superalloy bolted joint. As plotted in Figure 11, for the neat-fit joints, the final failure load shows a minor increase from $2815 \mathrm{~N}$ at $25^{\circ} \mathrm{C}$ to $2947 \mathrm{~N}$ at $150^{\circ} \mathrm{C}$, and then drops rapidly to $665 \mathrm{~N}$ when the temperature rises to $450^{\circ} \mathrm{C}$. As the bolt-hole clearance is $0.4 \%$, the load-bearing capacity of the joint varies little with temperature under $450^{\circ} \mathrm{C}$, while declining dramatically from $2908 \mathrm{~N}$ at $25^{\circ} \mathrm{C}$ to $1203 \mathrm{~N}$ at higher temperatures $750^{\circ} \mathrm{C}$. However, the failure load grows slightly first as the temperature rises from $25^{\circ} \mathrm{C}$ to $150^{\circ} \mathrm{C}$, and then reduces to the minimum value at $600^{\circ} \mathrm{C}$, and finally climbs a certain amount at $750^{\circ} \mathrm{C}$ for the $0.8 \%$ and $1.2 \%$ clearance cases. Such varying trend can be closely associated with the extent and magnitude of compression area of hole edge on the CMC plate under various temperatures as the structure is subjected to failure, as illustrated in Figure 12. Compared with larger clearance cases, the load- 


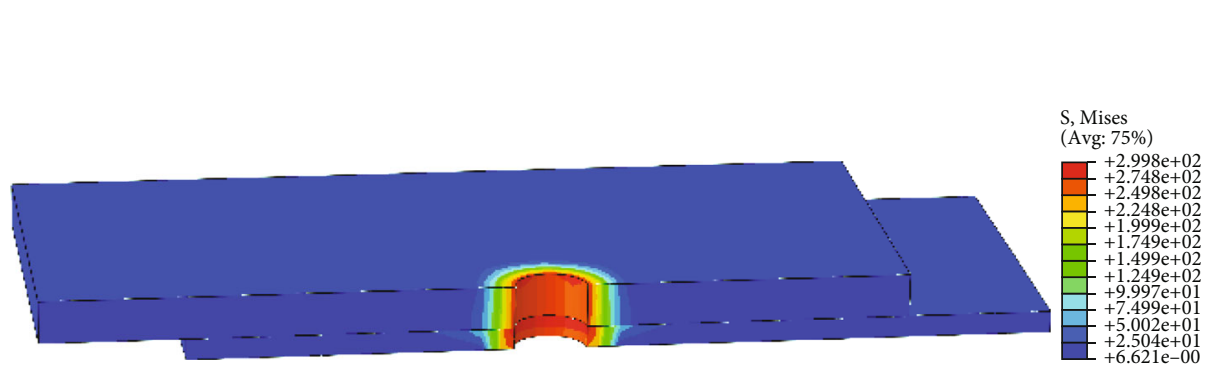

(a)

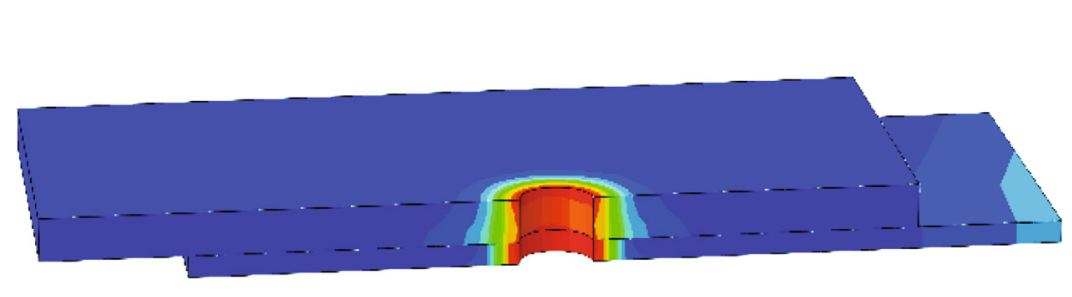

(c)

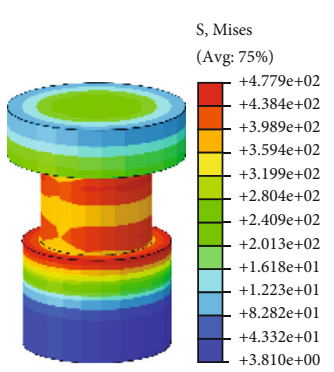

(b)

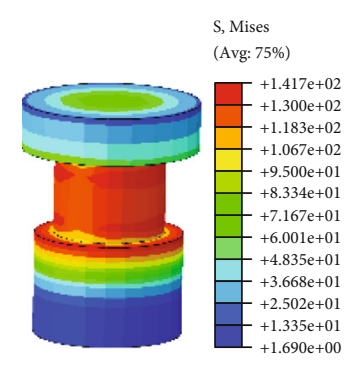

(d)

FIGURE 8: Mises stress contour map of the CMC and superalloy bolted joint with $1.2 \%$ clearance after applying preload and temperature but not tensile load. (a) CMC and superalloy plate at $20^{\circ} \mathrm{C}$. (b)Bolt and nut at $20^{\circ} \mathrm{C}$. (c) CMC and superalloy plate at $750^{\circ} \mathrm{C}$. (d) Bolt and nut at $750^{\circ} \mathrm{C}$.

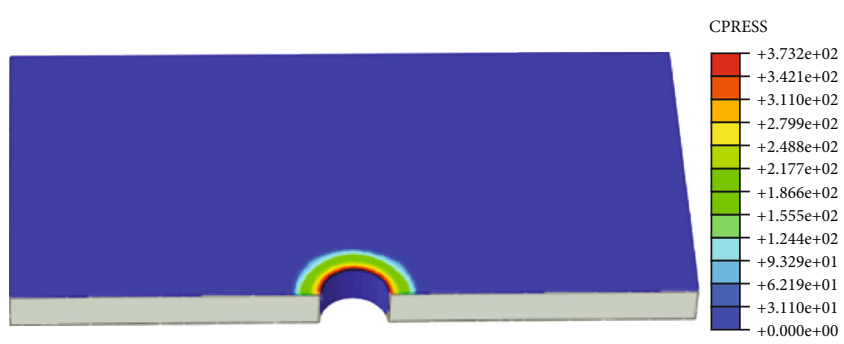

(a)

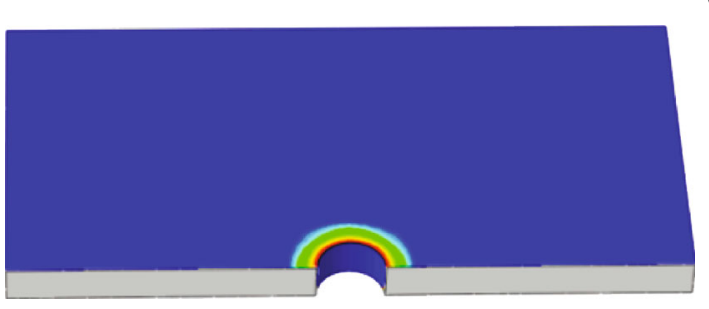

(c)

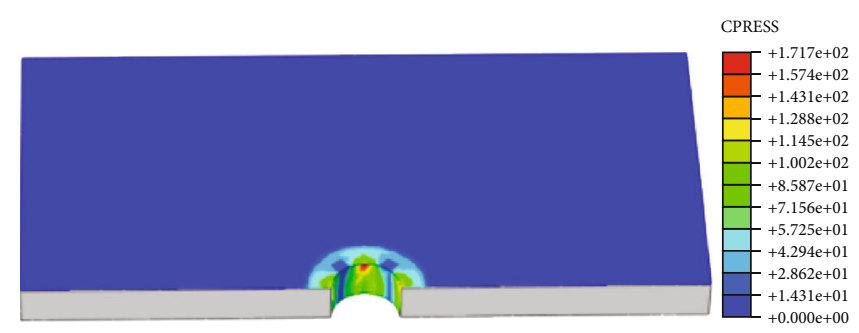

(b)

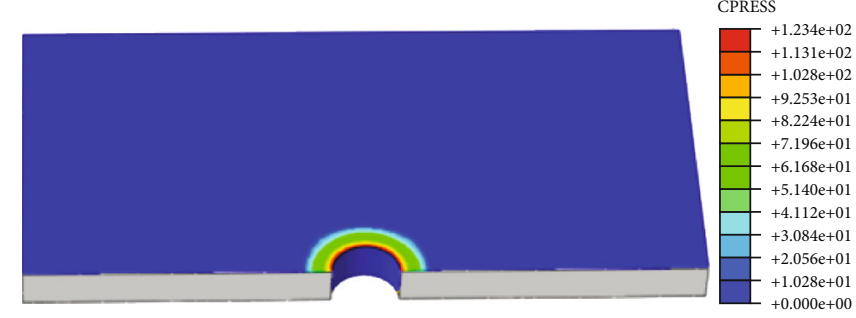

(d)

Figure 9: Comparison of contact compressive stress for the joint with $0.4 \%$ and $1.2 \%$ clearance after applying preload and temperature but not tensile load to the joint. (a) $f=0.4 \%, T=25^{\circ} \mathrm{C}$. (b) $f=0.4 \%, T=750^{\circ} \mathrm{C}$. (c) $f=1.2 \%, T=25^{\circ} \mathrm{C}$. (d) $f=1.2 \%, T=750^{\circ} \mathrm{C}$.

bearing capacity of the hybrid bolted joint is very sensitive to temperature when the initial clearance is small. For example, for neat-fit condition, there is a fivefold difference in the failure load as the temperature varies from $25^{\circ} \mathrm{C}$ to $450^{\circ} \mathrm{C}$. At the same temperature, which is higher than $300^{\circ} \mathrm{C}$, the loadbearing capacity is strengthened with the introduction of larger clearance to the bolt and hole of the joints. Several previous studies on single-bolt or pin-loaded fiber/polymer composite joints have shown that larger clearance can significantly affect bolt-hole contact area and peak stresses at the hole [29-40], leading to a decrease in the predicted joint strength. For example, McCarthy et al. [39] examined single-lap, single-bolt specimens made from high-strength graphite/epoxy laminates with quasi-isotropic and zerodominated lay-ups. Up to $14 \%$ loss in strength of the joint has been reported as the clearance ranging from neat-fit to the largest clearance of $240 \mu \mathrm{m}$. Pierron et al. [40] investigated woven glass fiber/epoxy joints loaded by $16 \mathrm{~mm}$ diameter pins with clearances ranging from $0.1 \mathrm{~mm}$ to $2 \mathrm{~mm}$, and they found that the failure load decreased by $30 \%$ from the 

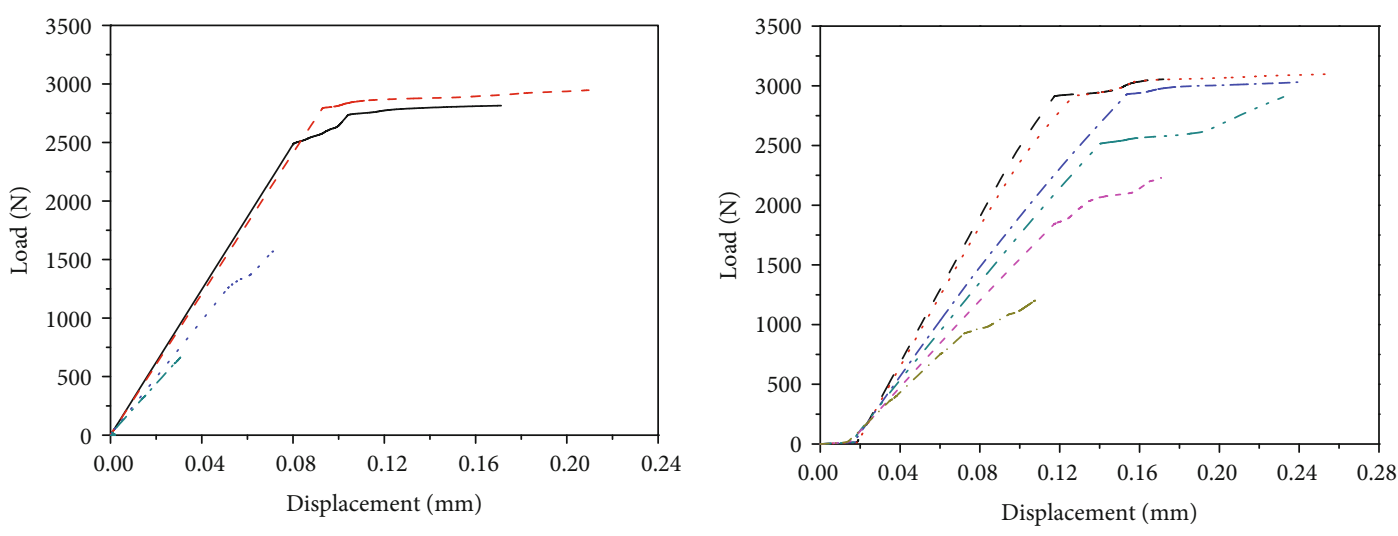

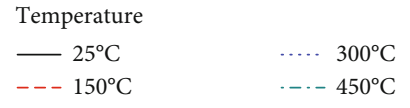

(a)

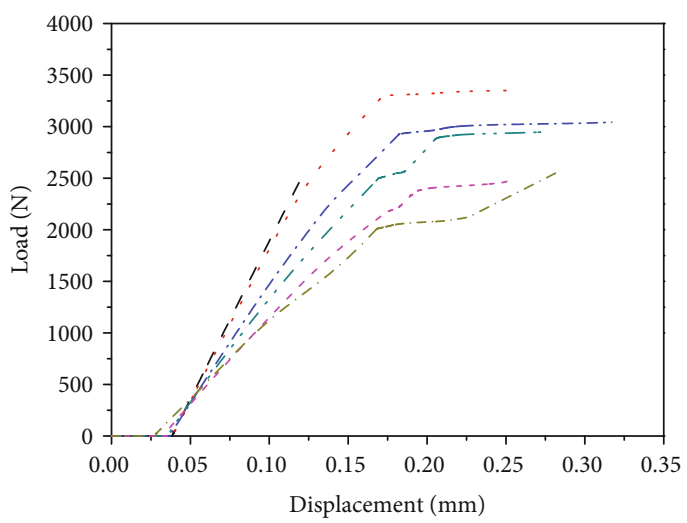

Temperature

- $25^{\circ} \mathrm{C}$

-... $150^{\circ} \mathrm{C}$

-. - $300^{\circ} \mathrm{C}$
-. $450^{\circ} \mathrm{C}$

-.. $600^{\circ} \mathrm{C}$

-. $750^{\circ} \mathrm{C}$

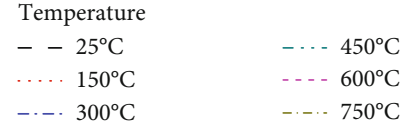

(b)

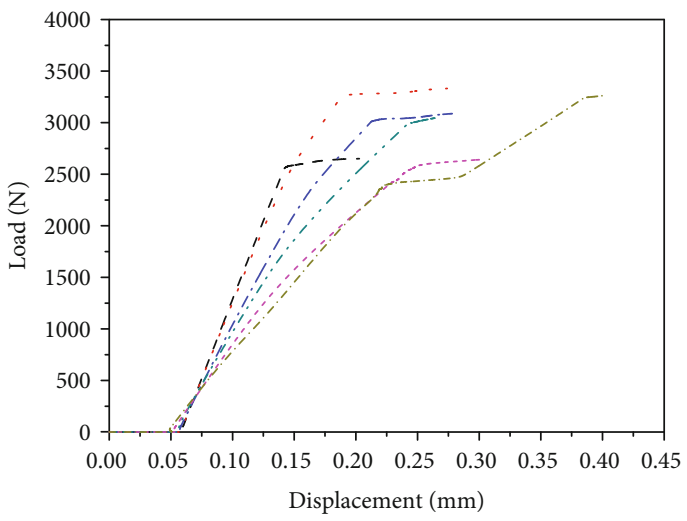

Temperature

$$
\begin{array}{ll}
--25^{\circ} \mathrm{C} & -\cdots 450^{\circ} \mathrm{C} \\
\ldots-150^{\circ} \mathrm{C} & -\cdots 600^{\circ} \mathrm{C} \\
\text {-. } 300^{\circ} \mathrm{C} & -.-750^{\circ} \mathrm{C}
\end{array}
$$

(d)

FIgURE 10: Load-displacement relationships for the hybrid C/SiC composite and superalloy bolted joint under various levels of bolt clearance. (a) $f=0$. (b) $f=0.4 \%$. (c) $f=0.8 \%$. (d) $f=1.2 \%$.

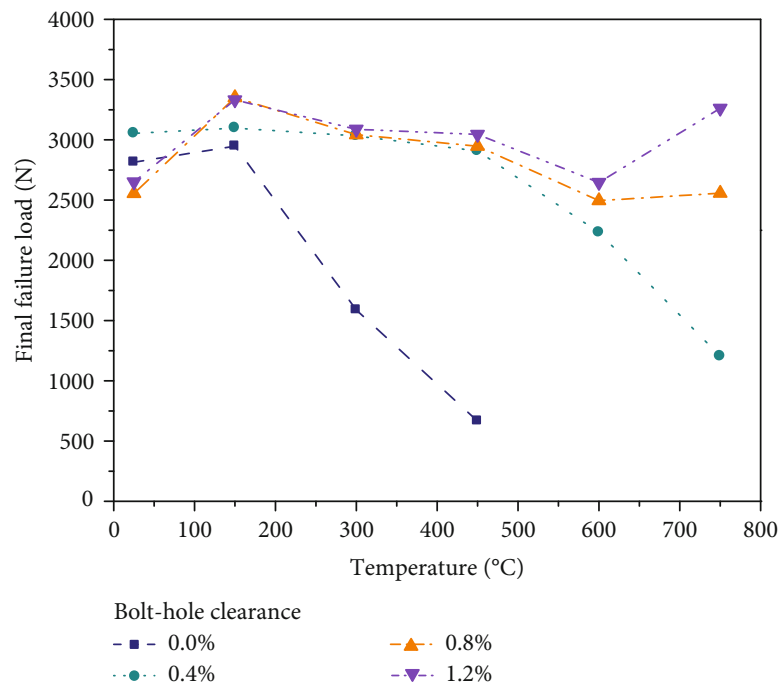

FIGURE 11: Variation of the failure load with temperature for the studied hybrid CMC/superalloy bolted joint. 


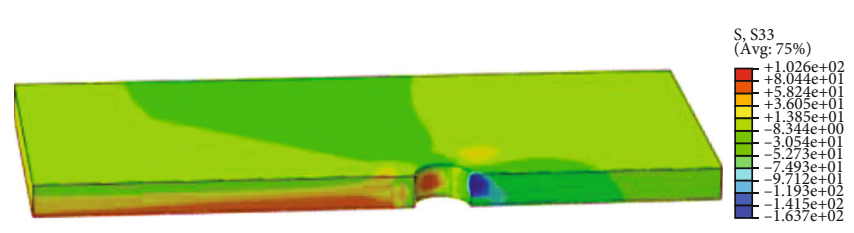

(a)

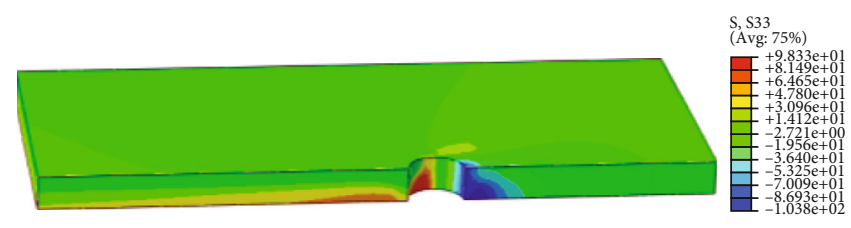

(c)

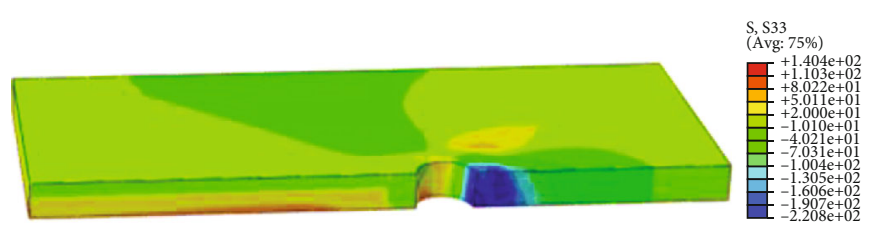

(b)

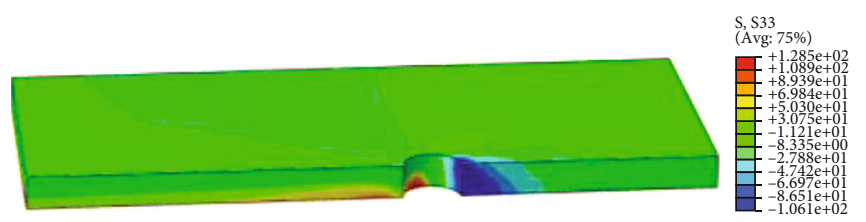

(d)

FIGURE 12: Axial stress contour maps of the composite plate for the joint with $1.2 \%$ clearance under various temperatures as the structure is subjected to failure. (a) $25^{\circ} \mathrm{C}$. (b) $150^{\circ} \mathrm{C}$. (c) $600^{\circ} \mathrm{C}$. (d) $750^{\circ} \mathrm{C}$.

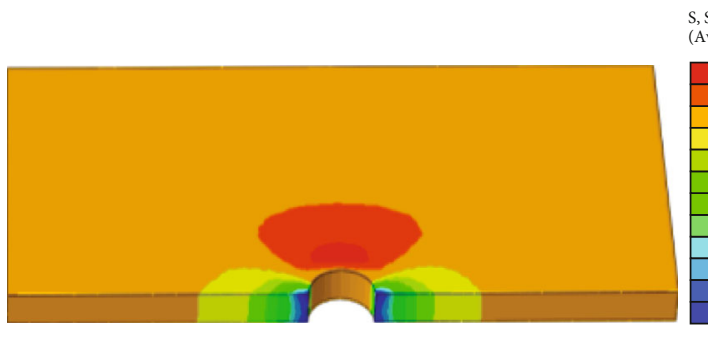

(a)

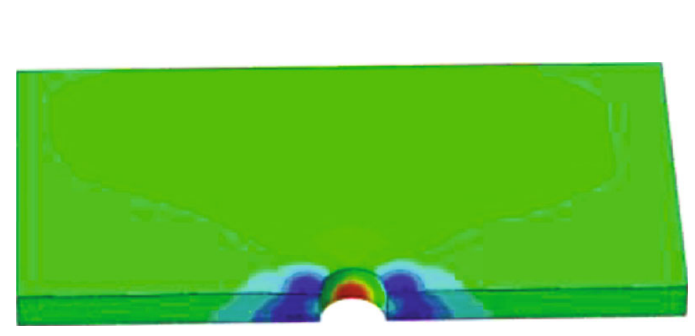

(c)

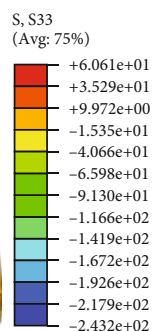

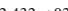

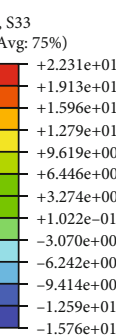

$-1.576 \mathrm{e}+01$

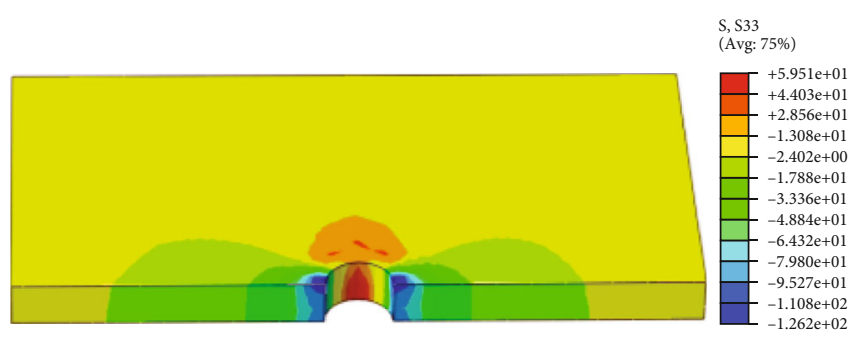

(b)

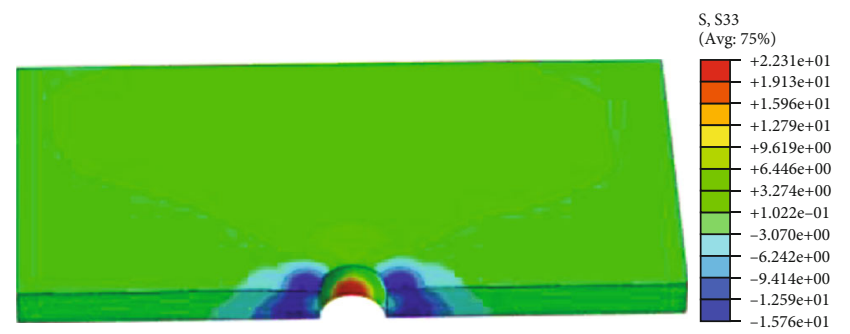

(d)

FIGURE 13: Axial stress contour maps of the composite plate under different clearance levels after applying preload and temperature but not tensile load to the joint at $750^{\circ} \mathrm{C}$ (a) $f=0$. (b) $f=0.4 \%$. (c) $f=0.8 \%$. (d) $f=1.2 \%$.

smallest to the largest clearance. Our findings seem to be different with such previous conclusions made at room temperature for polymer composite joints. For the studied hybrid $\mathrm{CMC}$ and superalloy bolted joints, as the bolt hole clearance increases, the bolt loads are transferred through a smaller area, resulting in more localized stresses and earlier damage formation around hole boundary. The load-bearing capacity should be lowered, as explained by many researchers [2940]. However, once the initial preload and temperature loads are imposed to the joint, there forms an initial thermal stress field within the structure. The axial thermal stress contour maps for the CMC plate with various clearance levels at $750^{\circ} \mathrm{C}$ after applying preload and temperature but not tensile load are depicted in Figure 13. As can be seen, the maximum compressive stress decreases from $243 \mathrm{MPa}$ for the neat-fit joint, and to $126 \mathrm{MPa}$ for $0.4 \%$ clearance and $15.8 \mathrm{MPa}$ for $0.8 \%$ and $1.2 \%$ clearances, accounting for $48 \%$ and $93 \%$ drop in comparison with the result for the neat-fit case. Such remarkable reduction in the peak compressive stresses has great potential to offset the weakening effect of the reduced contact area, explaining the elevated bearing performance of larger clearance-fit bolted joints at high temperatures. It is also indicated that there exists an optimal match in the bolt preload and bolt-hole clearance in maximizing the loadbearing capacity of the joint structure at each temperature, and the designed clearance is varying from $0.4 \%$ at $25^{\circ} \mathrm{C}$, $0.8 \%$ at $150^{\circ} \mathrm{C}$, and $1.2 \%$ at temperatures higher than $300^{\circ} \mathrm{C}$ if applying the same initial preload to the joints. Under $6000 \mathrm{~N}$ initial assembly preload, the joints attain the highest failure loads for the whole considered clearance range at $150^{\circ} \mathrm{C}$. To observe the failure progression within the $\mathrm{CMC}$ plate, the final failure areas around fastener hole are depicted with varying clearance at $25^{\circ} \mathrm{C}$ and $750^{\circ} \mathrm{C}$ in Figure 14 . At both temperatures, the number of failure elements of the CMC plate decreases with the rise of bolt-hole clearance value. This can also be reduced to the more concentrated 


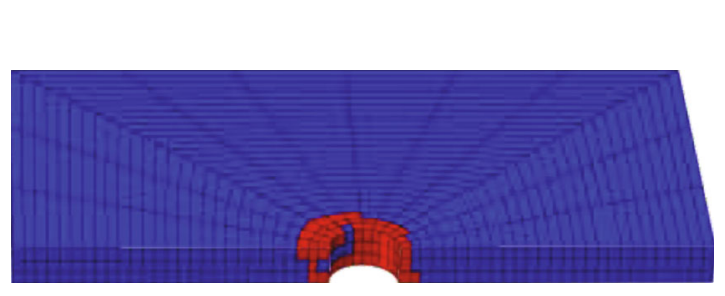

(a)

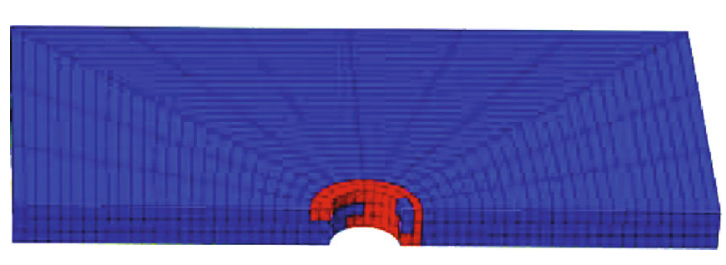

(c)

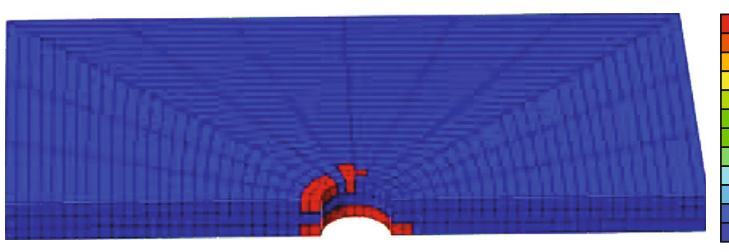

(e)

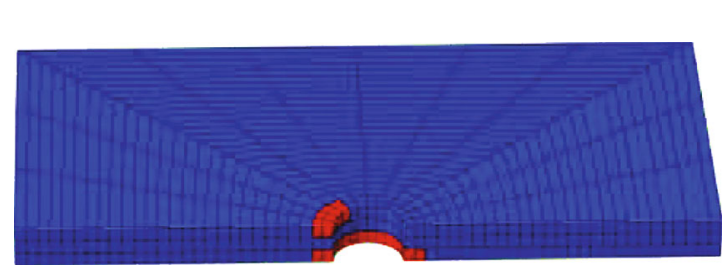

(g)

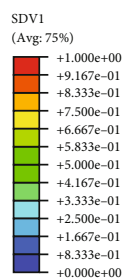

$+8.333 \mathrm{e}-01$

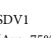

(Avg. $75 \%$

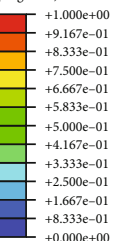

$+1.667 \mathrm{e}-01$
$+8.333 \mathrm{3}-01$
$+0.000 \mathrm{e}+00$

SDV

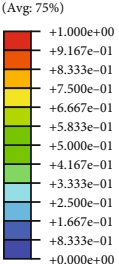

$+8.333 \mathrm{e}-01$
$+0.000 \mathrm{e}+00$

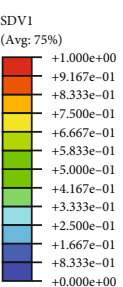

$+8.333 e-01$
$+0.000 e+00$

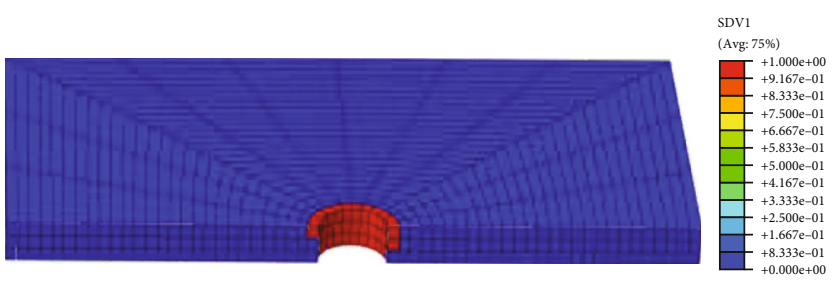

(b)

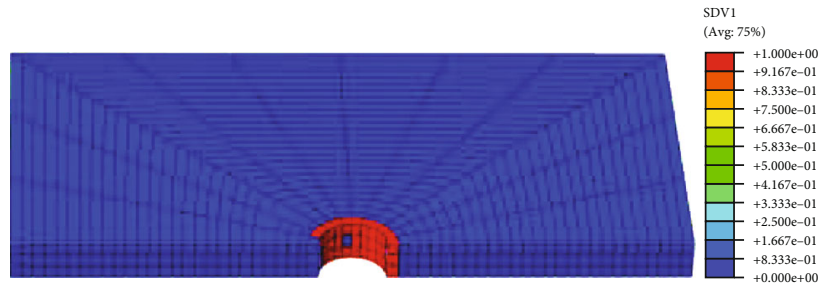

(d)

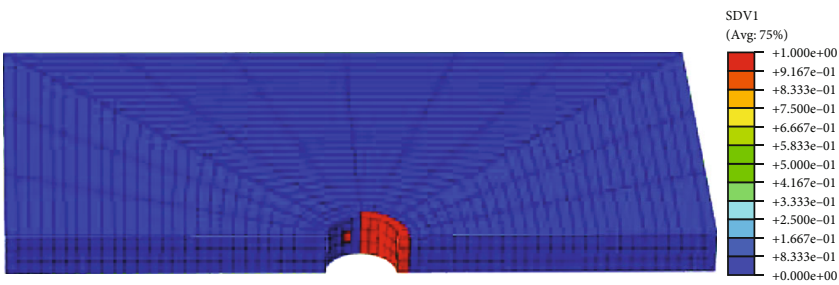

(f)

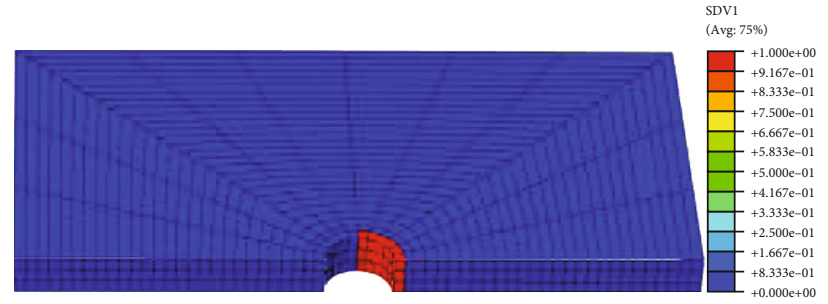

(h)

Figure 14: Final failure areas around fastener hole for the joint with various clearance levels at $25^{\circ} \mathrm{C}$ and $750^{\circ} \mathrm{C}$ (a) $f=0 \%, T=25^{\circ} \mathrm{C}$. (b) $f=0 \%, T=750^{\circ} \mathrm{C}$. (c) $f=0.4 \%, T=25^{\circ} \mathrm{C}$. (d) $f=0.4 \%, T=750^{\circ} \mathrm{C}$. (e) $f=0.8 \%, T=25^{\circ} \mathrm{C}$. (f) $f=0.8 \%, T=750^{\circ} \mathrm{C}$. $(\mathrm{g}) f=1.2 \%, T=25^{\circ} \mathrm{C}$; (h) $f=1.2 \%, T=750^{\circ} \mathrm{C}$.

stress on the laminate of the joint due to increasing clearance. Compared with the results at $25^{\circ} \mathrm{C}$, the reduced clamping force induced by thermal expansion mismatch of CMC and superalloy materials provides weaker "lateral support" for the fastening area, making the secondary bending effect more significant. And thus, the failure elements of composite material are mainly located on the inner surface of the CMC plate hole, and more concentrated on the right side with the climbing levels of bolthole clearance at $750^{\circ} \mathrm{C}$.

\section{Conclusions}

In the present work, a progressive damage model for $2 \mathrm{D}$ woven $\mathrm{C} / \mathrm{SiC}$ composite including a nonlinear macroscopic constituent model and Tsai-Wu failure criterion was established to predict high-temperature tensile performance and damage progression of single-lap, single-bolt hybrid $\mathrm{CMC} /$ superalloy joint. The failure analysis of the joint was implemented by using a user-defined subroutine UMAT embedded into the general package ABAQUS. The results showed that thermal expansion mismatch between the CMC and superalloy materials led to a dramatic decline in the assembly preload and adverse varying trends in the bolt-hole clearance of CMC and superalloy plates. As the temperature load was applied, there appeared a small interference between the CMC plate and bolt shank for the initial neat-fit case under $450^{\circ} \mathrm{C}$ and $0.4 \%$ clearance joint at $750^{\circ} \mathrm{C}$. Temperature has a significant effect on the tensile performance and damage progression of the joint structures. Under all bolt-hole clearance levels, the initial stiffness of the hybrid bolted joints decreases with the rise of applied temperature. However, the failure load varies significantly with the clearance level and exposed temperature for the studied hybrid $\mathrm{CMC} /$ superalloy bolted joint. With introducing larger clearance to the joint, the superposition of initial assembly stress and thermal stress is capable of offsetting the 
weakening effect of the reduced contact area, resulting in higher load-bearing capacity at sufficient higher temperature. There exists an optimal match in the initial assemble parameters to maximize the load-bearing capacity of the joint structure at each temperature or at the whole reference temperature range. The present work provides new findings on the effect mechanisms of temperature on thermostructural behavior and mechanical performance of the hybrid CMC/superalloy bolted joint, which are valuable for practical high-temperature application of ceramic matrix composites in next-generation aircrafts.

\section{Data Availability}

The data used to support the findings of this study are available from the corresponding authors upon request.

\section{Conflicts of Interest}

The authors declare that they have no conflicts of interest.

\section{Acknowledgments}

This work was supported by the Pre-Research Foundation of Shenyang Aircraft Design and Research Institute, Aviation Industry Corporation of China (Grant No. JH20128255).

\section{References}

[1] H. Hald, "CMC materials: from plasma channel testing to real capsule re-entry," Journal of High Temperature Chemical Processes, vol. 3, no. 2, pp. 153-165, 1994.

[2] T. Reimer, "The KERAMIK thermal protection system experiment on the FOTON M2 Mission," in Proceedings of the 5th European workshop on thermal protection systems and hot structures (SP-631), Noordwijk. The Netherlands, May 2006.

[3] A. Gülhan, F. Siebe, H. Weihs et al., "The sharp edge flight experiment - a mission overview," in Proceedings of the 5th European workshop on thermal protection systems and hot structures (SP-631), May 2006Noordwijk, The Netherlands.

[4] R. Naslain, "Design, preparation and properties of non-oxide CMCs for application in engines and nuclear reactors: an overview," Computer Science and Technology, vol. 64, no. 2, pp. 155-170, 2004.

[5] D. Hansel, H. Hald, and F. Ruhle, Development of a Joining Method for High Temperature Constructions, ESA SP-428, ESA, Paris, 1999.

[6] M. Dogigli, K. Handrick, M. Bickel, and A. Frohlich, CMC Key Technologies-Background, Status, Present and Future Applications. ESA SP-521, ESA, Paris, 2003.

[7] H. Bohrk and U. Beyermann, "Secure tightening of a CMC fastener for the heat shield of re-entry vehicles," Composite Structures, vol. 92, no. 1, pp. 107-112, 2010.

[8] H. Mei, L. F. Cheng, Q. Q. Ke, and L. T. Zhang, "High-temperature tensile properties and oxidation behavior of carbon fiber reinforced silicon carbide bolts in a simulated re-entry environment," Carbon, vol. 48, no. 11, pp. 3007-3013, 2010.

[9] G. D. Li, X. F. Wu, C. R. Zhang, H. F. Hu, Y. D. Zhang, and Z. B. Zhang, "Theoretical simulation and experimental verification of $\mathrm{C} / \mathrm{SiC}$ joints with pins or bolts," Materials and Design, vol. 53, pp. 1071-1076, 2014.
[10] L. B. Zhao, W. Yang, T. C. Cao et al., "A progressive failure analysis of all-C/SiC composite multi-bolt joints," Composite Structures, vol. 202, pp. 1059-1068, 2018.

[11] L. Hahn, F. Ansorge, and A. Bruckner-Foit, "Damage and failure behaviour of a woven $\mathrm{C} / \mathrm{SiC}$ material," Journal of Materials Science, vol. 32, no. 20, pp. 5467-5475, 1997.

[12] S. Baste, "Inelastic behaviour of ceramic-matrix composites," Composites Science and Technology, vol. 61, no. 15, pp. 22852297, 2001.

[13] L. Jun, Research on the Nonlinear Constitutive Relationship of $2 \mathrm{D} \mathrm{C/SiC} \mathrm{Composites,} \mathrm{Northwestern} \mathrm{Polytechnical} \mathrm{University,}$ 2014.

[14] J. F. Maire and J. L. Chaboche, "A new formulation of continuum damage mechanics (CDM) for composite materials," Aerospace Science and Technology, vol. 1, no. 4, pp. 247-257, 1997.

[15] X. G. Gao, L. Li, and Y. D. Song, “A temperature-dependent constitutive model for fiber-reinforced ceramic matrix composites and structural stress analysis," International Journal of Damage Mechanics, vol. 23, no. 4, pp. 507-522, 2014.

[16] A. G. Evans, J. M. Domergue, and E. Vagaggini, "Methodology for relating the tensile constitutive behavior of ceramic-matrix composites to constituent properties," Journal of the American Ceramic Society, vol. 77, no. 6, pp. 1425-1435, 1994.

[17] S. K. Mital, P. L. N. Murthy, and C. C. Chamis, "Computational simulation of continuous fiber reinforced ceramic matrix composites behavior," Journal of Advanced Materials, vol. 32, no. 1, pp. 46-59, 2000.

[18] J. L. Chaboche and J. F. Maire, "New progress in micromechanics-based CDM models and their application to CMCs," Composites Science and Technology, vol. 61, no. 15, pp. 2239-2246, 2001.

[19] H. Ismar, F. Schroter, and F. Streicher, "Influence of the fiber volume fraction and the fiber Weibull modul on the behavior of $2 \mathrm{D}$ woven $\mathrm{SiC} / \mathrm{SiC}$ ? a finite element simulation," Acta Mechanica, vol. 149, no. 1-4, pp. 41-54, 2001.

[20] S. K. Mital, P. L. N. Murthy, and C. C. Chamis, "Simplified micromechanics of plain weave composites," Journal of Advanced Materials -Covina, vol. 33, pp. 10-17, 2001.

[21] J. P. Solti, S. Mall, and D. D. Robertson, "Modeling damage in unidirectional ceramic-matrix composites," Composites Science and Technology, vol. 54, no. 1, pp. 55-66, 1995.

[22] T. Sadowski and L. Marsavina, "Multiscale modelling of twophase ceramic matrix composites," Computational Materials Science, vol. 50, no. 4, pp. 1336-1346, 2011.

[23] A. Coradi, G. Couégnat, E. Martin, and F. Mahdi, “A multiscale damage model for the mechanical behaviour of ceramic matrix composite materials.," in ECCM 2012 - Composites at Venice, Proceedings of the 15th European Conference on Composite Materials.

[24] L. Saucedo-Mora and T. J. Marrow, "Multi-scale damage modelling in a ceramic matrix composite using a finiteelement microstructure meshfree methodology," Philosophical Transactions of the Royal Society A: Mathematical, Physical and Engineering Sciences, vol. 374, no. 2071, article 20150276, 2016.

[25] "Editorial committee on China aviation materials handbook," in China Aviation Materials Handbook, China Standards Press, 2002.

[26] S. Y. Zhao, Z. Y. Li, Z. L. Pu, X. Y. Sun, and W. J. Zhang, "Thermal stress and assembling parameters evolution of CMC 
bolted joint under transient thermal loads," Journal of Harbin Institute of Technology (New Series).

[27] S. W. Tsai and E. M. Wu, "A general theory of strength for anisotropic materials," Journal of Composite Materials, vol. 5, no. 1, pp. 58-80, 1971.

[28] I. F. Soykok, O. Sayman, M. Ozen, and B. Korkmaz, "Failure analysis of mechanically fastened glass fiber/epoxy composite joints under thermal effects," Composites: Part B, vol. 45, no. 1, pp. 192-199, 2013.

[29] C. T. McCarthy and M. A. McCarthy, "Three-dimensional finite element analysis of single-bolt, single-lap composite bolted joints: Part II-effects of bolt-hole clearance," Composite Structures, vol. 71, no. 2, pp. 159-175, 2005.

[30] C. T. McCarthy, M. A. McCarthy, and V. P. Lawlor, "Progressive damage analysis of multi-bolt composite joints with variable bolt-hole clearances," Composites Part B: Engineering, vol. 36, no. 4, pp. 290-305, 2005.

[31] T. L. Qin, L. B. Zhao, and J. Y. Zhang, "Fastener effects on mechanical behaviors of double-lap composite joints," Composite Structures, vol. 100, pp. 413-423, 2013.

[32] M. Chishti, C. H. Wang, R. S. Thomson, and A. C. Orifici, "Numerical analysis of damage progression and strength of countersunk composite joints," Composite Structures, vol. 94, no. 2, pp. 643-653, 2012.

[33] M. Chishti, C. H. Wang, R. S. Thomson, and A. C. Orifici, "Experimental investigation of damage progression and strength of countersunk composite joints," Composite Structures, vol. 94, no. 3, pp. 865-873, 2012.

[34] M. W. Hyer, E. C. Klang, and D. E. Cooper, "The effects of pin elasticity, clearance, and friction on the stresses in a pin-loaded orthotropic plate," Journal of Composite Materials, vol. 21, no. 3, pp. 190-206, 1987.

[35] V. Kradinov, A. Barut, E. Madenci, and D. R. Ambur, "Bolted double-lap composite joints under mechanical and thermal loading," International Journal of Solids and Structures, vol. 38, no. 44-45, pp. 7801-7837, 2001.

[36] R. A. Naik and J. H. Crews Jr., "Stress analysis method for a clearance-fit bolt under bearing loads," AIAA Journal, vol. 24, no. 8, pp. 1348-1353, 1986.

[37] W. H. Chen, S. S. Lee, and J. T. Yeh, "Three-dimensional contact stress analysis of a composite laminate with bolted joint," Composite Structures, vol. 30, no. 3, pp. 287-297, 1995.

[38] M. A. McCarthy and C. T. McCarthy, "Finite element analysis of effects of clearance on single shear composite bolted joints," Plastics, Rubber and Composites, vol. 32, no. 2, pp. 65-70, 2003.

[39] M. A. McCarthy, V. P. Lawlor, W. F. Stanley, and C. T. McCarthy, "Bolt-hole clearance effects and strength criteria in singlebolt, single-lap, composite bolted joints," Composites Science and Technology, vol. 62, no. 10-11, pp. 1415-1431, 2002.

[40] F. Pierron, F. Cerisier, and M. Grediac, "A numerical and experimental study of woven composite pin-joints," Journal of Composite Materials, vol. 34, no. 12, pp. 1028-1054, 2000. 